\title{
Impact of the Introduction of the Social Long-Term Care Insurance in Germany on Financial Security Assessment in Case of Long-Term Care Need*
}

\author{
Andy Zuchandke ${ }^{\mathrm{a}}$, Sebastian Reddemann ${ }^{\mathrm{b}}$, Simone Krummaker ${ }^{\mathrm{b}}$ and \\ J.-Matthias Graf von der Schulenburg ${ }^{\mathrm{a}, \mathrm{b}}$ \\ ${ }^{a}$ Institute for Risk and Insurance, Leibniz Universität Hannover, Königsworther Platz 1, Hannover, \\ Niedersachsen D-30167, Germany. \\ E-mail: az@ivbl.uni-hannover.de \\ ${ }^{\mathrm{b}}$ Center for Risk and Insurance, Leibniz Universität Hannover, Königsworther Platz 1, Hannover, \\ Niedersachsen D-30167, Germany.
}

The discussion concerning long-term care insurance in Germany barely exceeds the financial state of the social system. The view of the insured involved is largely ignored. This paper analyses the effect of the introduction of compulsory long-term care insurance in 1995 in Germany on the perception of financial security when needing long-term care. Using different regression techniques on a subset of the German Socio-Economic Panel (SOEP) data, we show that the introduction led to a general positive shift of the assessment. Furthermore, experience with long-term care had no significant effect before the introduction but a positive effect afterwards. Also, the perception of financial security is found to be increasing with income at both times with similar magnitudes.

The Geneva Papers (2010) 35, 626-643. doi:10.1057/gpp.2010.26

Keywords: long-term care insurance; social insurance; risk perception; introduction; Germany

\section{Introduction}

The potential need for long-term care is one of the greatest financial risks faced by the elderly and their adult children. As traditional structures of the family evolve towards one-generation households and female employment rates increase, family members are increasingly unable to provide long-term care. As a result, institutional care must be organised and paid for, or family members may have to interrupt their employment. Both alternatives result in financial risks that emerge from long-term care risk. In Germany, as well as in France and Austria, adult children are legally obligated to support their parents if the parents have exhausted their financial resources.

Following a large debate in Germany since the 1970s, compulsory long-term care insurance was introduced in 1995 as the fifth pillar of social insurance and was structured as a pay-as-you-go system. After several efforts to reform this system,

*We wish to thank two anonymous referees for their helpful comments. 
which suffered from severe financial problems, long-term care insurance reform in Germany is currently widely discussed. Several measures were proposed by a number of institutions, leaving the future of the programme in an uncertain state. Most discussions have centred on the state of social funds while mostly neglecting the mindset of the affected segment of the population. The recent debate on reforming the social long-term care insurance scheme received renewed attention in September 2009 from the new German government, but several concrete steps still remain.

The development and implementation of social long-term care insurance in Germany appears to be primarily dominated by fiscal, rather than socio-political arguments, as the disburdening of the communities from long-term care insurance payments has been one of the main arguments in the discussions.

Existant literature primarily focuses on analysing appropriate designs for a longterm care system. These designs incorporate financial structures and apply theories of demand. ${ }^{1}$ Kunreuther ${ }^{2}$ states that high loss/low probability events that have not occurred recently are likely to be ignored, which plays an important role in risk assessment. Hershey et $a l .{ }^{3}$ applied this theory to health insurance. Pauly ${ }^{4}$ suggests an underestimation of needs by uninformed elderly individuals. Moreover, he finds nonrational demand for long-term care insurance, which is motivated by second-stage moral hazard behaviour between parents and children and by consumption reasons in the case of death of a partner. Zweifel and Struewe ${ }^{5}$ built a two-generation model for long-term care insurance based on this theory. Holtgrave and Weber ${ }^{6}$ state that most of the risks considered by research on risk perception fall into the two categories: health and financial risk. Moreover, most of the health risks include a financial component. There are rarely studies that assess the financial aspects and also recommend a new insurance scheme to implement.

In our paper, we focus on the perception of financial aspects concerning long-term care risks. We aim to investigate whether the introduction of compulsory long-term care insurance in Germany affects the individual assessment of the financial implications of long-term care risks. This is performed by conducting regression analysis on a fitting subsample of observations from the German socio-economic panel before and after the introduction of long-term care insurance. Therefore, we evaluate the perception of financial risk when needing long-term care, but we do not estimate the individual probability of long-term care risk. Our three hypotheses are embedded in the general question of the impact of social long-term care insurance in a given setting.

\footnotetext{
${ }^{1}$ German studies are found in Breyer (1991,1992), Buchholz and Wiegard (1992) and Eisen (1992); international studies are found in Courbage and Roudaut (2008), Guillén and Pinquet (2008), CostaFont et al. (2008), Parker and Clarke (1997), Brown and Finkelstein (2007) and Doerpinghaus and Gustavson (2002).

${ }^{2}$ Kunreuther (1978).

${ }^{3}$ Hershey et al. (1984).

${ }^{4}$ Pauly (1990).

${ }^{5}$ Zweifel and Struewe (1998).

${ }^{6}$ Holtgrave and Weber (1993).
} 
As there are no empirical studies focussing on introductory effects of insurance systems on individual perception, we are able to discover new insights as to how the introduction itself, and other variables, influence the individual financial assessment regarding facing personal high-probability risks. Our study helps to understand whether the public adopts this new pillar of social security and whether the new financial burdens that result from paying additional premiums are viewed as acceptable given the reduction of other long-term financial risks. The answer to the question of acceptance provides useful input for the discussion of changing the current system to a funded scheme.

The paper is structured as follows. After this introduction, an overview of German long-term care insurance is given. In the next section, the methodology and data are described, and the hypotheses are constructed. The regression results are presented in the subsequent section and discussed against the background of the derived research questions. The final section summarises the results, deduces possible implications and hints towards further research questions.

\section{Overview of German social long-term care insurance}

Compulsory long-term care insurance in Germany was implemented in 1995 after 20 years of political discussion. The aim was to treat the risk of long-term care as an existential risk (such as retirement, sickness, unemployment and disability) and roll the programme into social security. Before the installation of social long-term care insurance, whereas acute care was covered by health insurance, long-term care was covered only for the needy through a community-based, means-tested programme. This programme (Hilfe zur Pflege) only provides benefits if the recipient has exhausted all private assets and income resources. Private care insurance has been available in Germany since the mid-1980s but played a minor role in covering long-term care risk due to low demand (only 250,000 private contracts were purchased). ${ }^{7}$

Prior to the introduction of social long-term care insurance, most of the chronically ill or elderly individuals in need of long-term care were dependent on payments from social assistance. Approximately 80 per cent of nursing home residents financed their care by means-tested social assistance. In addition, the number of eligible persons rose from 165,000 in 1963 to nearly 660,000 in $1993 .{ }^{8}$ Long-term care was a large and growing financial burden for communities, and German Reunification exacerbated the problems of financing long-term care. Figure 1 displays the increase in the number of beneficiaries when long-term care social assistance was implemented. The introduction of the social long-term care insurance programme in 1995 led to a downward shift in the curve as a result of a massive shift from community-financed social assistance to the new insurance scheme.

The mandatory social insurance programme for long-term care was established in 1995 as the fifth pillar of the social security scheme in Germany to protect the population against the financial hardship associated with disability and chronic illness. The government initially implemented social long-term care insurance to cover nursing

\footnotetext{
${ }^{7}$ Goetting et al. (1994, p. 289) and Zweifel and Struewe (1998, p. 13ff.).

${ }^{8}$ Statistisches Bundesamt (2009).
} 


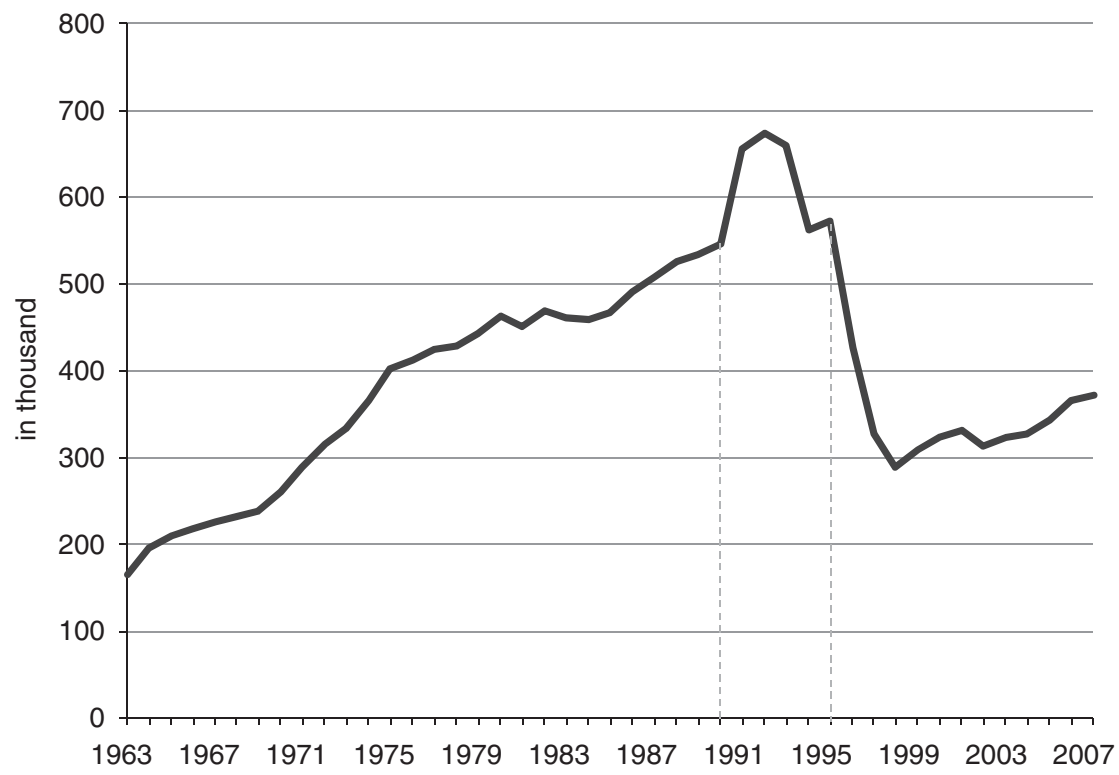

Figure 1. Recipients of social assistance for long-term care (Hilfe zur Pflege) 1963-2007 (Statistisches Bundesamt, 2009, Table D7).

care dependency, to disburden the local authorities from increasing payments to provide social assistance and to enhance ambulatory care for long-term care patients. These goals were mostly achieved. ${ }^{9}$

Social long-term care insurance was designed as a pay-as-you-go system and was financed by income-related contributions, which are split equally between employees and employers. The initial contribution rate in 1995 was 1 per cent. The new social insurance programme provides home care and nursing home care for people with a medically approved need without regard to age or financial status and without requiring a means test. The benefits are fixed at a monthly maximum per eligible person and are determined by illness/disability level and the setting. ${ }^{10}$ After the implementation in January 1995, benefits for home care were paid in cash or in kind beginning in July 1995, and benefits for nursing home care were added in July 1996. ${ }^{11}$ The administration of social long-term care insurance was connected to the existing public health insurance fund and covers the same people (approximately 90 per cent of the population $^{12}$ ). In 1996 , the contribution rate was raised to 1.7 per cent due to the extension of benefits on institutional care. The rate was raised again to 1.95 per cent

${ }^{9}$ BMGS (2003, p. 186) and Geraedts et al. (2000, p. 395).

${ }^{10}$ BMG (2008a, pp. 11-12 and 23).

11 BMGS (2003, p. 185).

12 OECD (2008, p. 19). Individuals with high income and covered by private health insurance schemes were obliged to purchase long-term care insurance at the same private insurance company with the same range of coverage as the public scheme. 


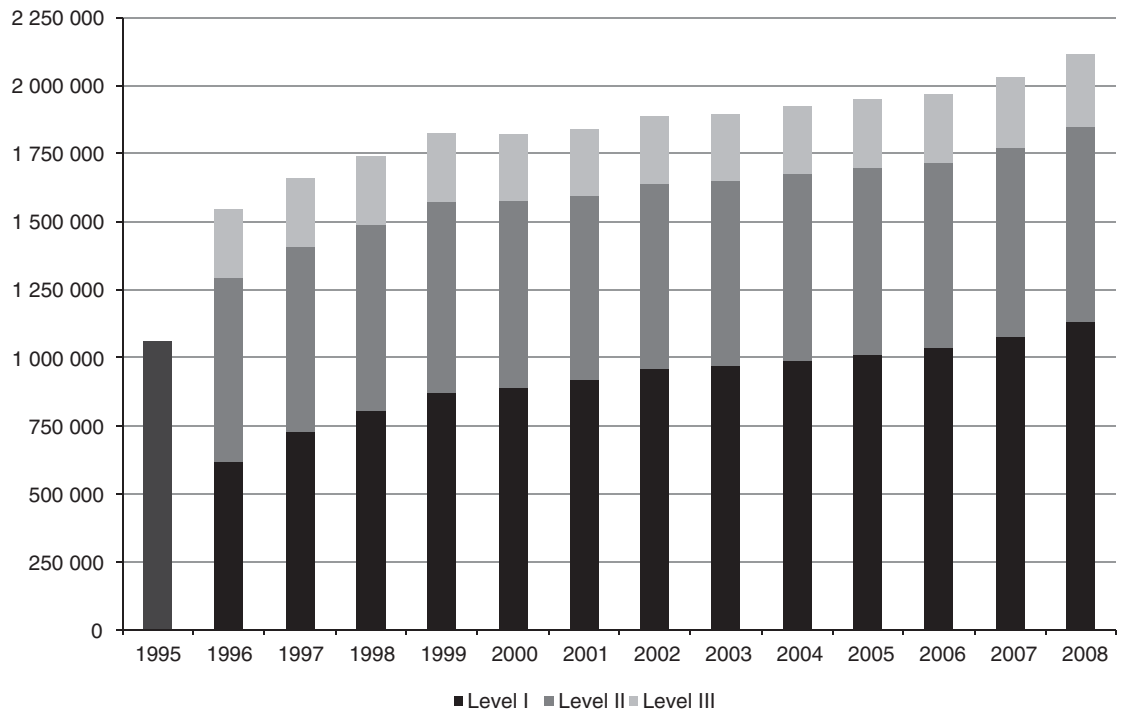

Figure 2. Recipients of long-term care (1995 only recipient in total available) (BMG, 2008b).

in 1998. The benefit and contribution structure has been relatively stable since then, excluding minor modifications.

Figure 1 illustrates that up to 400,000 individuals are dependent on both social assistance and social long-term care insurance. This is based on the fact that social long-term care insurance provides defined benefits (the limit of which depends on the disability level) ${ }^{13}$ and form of care (home or institutional). Therefore, the provided benefits or services often only cover part of an individual's needs. ${ }^{14}$ If the personal wealth of the aggrieved individuals or their potentially liable relatives cannot completely cover the costs for needed care, they can also apply for social assistance. ${ }^{15}$

While the purpose of health insurance is to improve existing health conditions, long-term care aims at making current conditions more bearable. As displayed in Figure 2, more than two million people currently received monthly benefits from social long-term care insurance. Most of these people receive ambulatory benefits ( 1.53 million). Stationary care in nursing homes is used by 720,000 people. As the probability of becoming dependent on long-term care after the age of 80 years is approximately 29 per cent, it is expected that in the year 2030, 3.09 million people will be in need of long-term care. ${ }^{16}$

As the long-term care insurance programme began to run a deficit in 1999 and was forecasted to have exhausted any prior surplus by 2008, the German government

\footnotetext{
${ }^{13}$ The eligibility for benefits is distinguished by three levels of need and based on limitations for a minimum of six months in activities of daily living (ADL) and instrumental activities of daily living (IADL).

${ }^{14}$ BMGS (2003, pp. 185-186.)

${ }^{15}$ BMG (2008a).

${ }^{16}$ BMG (2009b, p. 15).
} 
initiated several small reforms. ${ }^{17}$ Connected with the newly elected government in 2009, the discussion about the financial deficit and the long-term care insurance system resumed.

\section{Data, methodology and hypotheses}

The data used in this publication was made available by the German Socio-Economic Panel Study (SOEP) at the German Institute for Economic Research (DIW), Berlin. The German Socio-Economic Panel is a representative panel survey of households and individuals. The first questioning was performed in 1984, covering approximately 6,000 households and 12,000 individual respondents. In 2008, the $26^{\text {th }}$ questioning was performed, which included nearly 11,000 households and 20,000 individuals. The survey covers a wide range of diverse topics, such as income, employment status, education and health situation. ${ }^{18}$

The aim of our paper is to analyse the individual assessment of financial risk associated with long-term care dependency. The SOEP contains questions about individual perceptions of the risks inherent to unemployment, old-age, long-term care, etc. and information about income and other socioeconomic factors. We, therefore, use the following question and the outcomes included in the SOEP survey as a proxy for individual perception of the financial risks associated with long-term care:

The social security system in the FRG is split into several branches: health care, unemployment insurance and pension insurance. The social security system and its corresponding private businesses exist to provide assistance during emergencies and old age. How financially secure are you in the following situations?

Only the answers concerning long-term care dependency are used in the regression analysis as we aim to investigate the impact of the implementation of the social long-term care insurance. Potential answers are divided into five categories, from "very good" to "bad", in addition to "don't know/does not apply". We transformed the answers into a numerical scale from 1 to 5 , where 1 corresponds to "bad" and 5 corresponds to "very good" (we dropped observations with the answer "don't know/does not apply" as they had no relevance). The SOEP includes this specific question every five years, beginning in 1987. To analyse the effect of implementing compulsory long-term care insurance, we use a balanced data set from 1992, 1997 and 2002. The answers from 2002 and 1997 were used to ensure not only the detection of direct (short-term) effects (e.g., broad media coverage or introductory problems) but also the long-term effects from the introduction. Our sample consists of members of the German health insurance system, either compulsory or private. All participants are aged 16 years or older. The final data set includes approximately 18,000 observations.

\footnotetext{
${ }^{17}$ BMGS (2003) and BMG (2009a).

${ }^{18}$ A detailed description of the SOEP can be found in Wagner et al. (2007).
} 
To examine our research questions, we estimate the following regression equation:

$$
\overrightarrow{F S_{t}}=\vec{\beta} \cdot X_{t}+\vec{\varepsilon}_{t}
$$

where $\overrightarrow{F S_{t}}$ is the vector of individual perception of financial security with respect to long-term care need at time $t$. The matrix $X_{t}$ includes all variables inevitable to test our hypotheses and a set of control variables. The vector $\overrightarrow{\varepsilon_{t}}$ represents the error terms.

According to the ordinal scale of our dependent variable, we use an ordered probit regression based on the latent variable approach ${ }^{19}$ to estimate Eq. (1). In our analysis, we focus on relative comparisons and on coefficient signs rather than absolute values. We also do not calculate marginal effects to interpret the results, as marginal effects represent the probability that the individual $i$ changes the former category of the dependent variable, given a marginal change in an explanatory variable. Such information does not deliver further information to analyse our hypotheses.

To analyse structural breaks of individual risk perception caused by the introduction of compulsory long-term care insurance and the significance of these influences, we ran separate regressions at all observed points in time. First, we look at shifts in perception due to the introduction of compulsory long-term care insurance by adding year dummy variables $\mu_{t}$ and their interaction terms with all other explanatory variables (excluding control variables) to the variable-matrix $X_{t}$ and estimate Eq. (1) employing a pooled ordered probit regression. The year dummy variables $\mu_{t}$ have a value of one at time $t$ and zero otherwise. In the second step, we estimate Eq. (1) separately for 1992, 1997 and 2002 to focus on the significance level of the influences at each point in time.

Using our regressions, we will analyse the estimation results with regard to our three hypotheses covering different aspects of the influence of introducing compulsory long-term care insurance in Germany.

\section{Motivation and formulation of hypotheses}

As mentioned in the section 'Overview of German social long-term care insurance', the implementation of long-term care insurance in 1995 exerted influence on the financial situation of those in need of long-term care. The new system covers the financial risk associated with becoming dependent on long-term care by offering monetary assistance. Beforehand, people had to completely deplete their earnings to finance their care needs and the majority of people obtaining care in institutions were dependent on social assistance sooner or later. Owing to these financial aspects and individual risk aversion, we expect the following results:

H1: The introduction of long-term care insurance in 1995 led to a general positive shift in individuals' assessment of their financial situation in the case of longterm care need. In terms of our regression, the year dummy variables $\mu_{t}$ will be positive and significantly different from zero.

\footnotetext{
${ }^{19}$ For a detailed description of this approach, see Winkelmann and Boes (2006, ch. 6).
} 
H2: An individual's assessment of their financial situation increases with income both before and after introducing long-term care insurance. Therefore, all income coefficients are positive and significantly different from zero. Furthermore, the financial support of compulsory long-term care insurance weakens the influence of income, leading to significantly negative coefficients for the respective interaction terms.

Hypothesis 3 (H3) arises from the insight that the perception of long-term care risk is based on prospects that are influenced by a number of different factors. One important factor is the level of information about financial consequences in the case of long-term care need. The SOEP survey provides information on whether someone in the respondent's household needs care on a constant basis. This direct experience with the psychological, physical and financial aspects of long-term care leads to a higher level of information for the relevant respondent. Weinstein describes a bias in personal risk perception, arguing that less informed individuals believe that they are less likely to be affected by risks or situations than the average individual. ${ }^{20}$ This bias might partly be reduced if the individual has experience with long-term care, resulting in a worse perception in 1992 compared to individuals with no experience. In addition, McCall et $a .^{21}$ found the demand for long-term care insurance significantly increases with long-term care experience. This additional demand may be covered by the newly introduced insurance, leading to a better assessment in 1997 and 2002.

H3: Experience with long-term care in a respondent's household has a negative effect on the assessment of their financial situation. After the introduction of compulsory long-term care insurance, this negative effect was diminished. In our pooled regression, this would imply that the coefficient of experiencing long-term care has a negative sign and is significantly different from zero. Conversely, the respective interaction terms are positive and significantly different from zero.

\section{Variables}

To analyse our hypotheses, we include the following variables:

"Income" is a natural variable for inclusion; we decided to use per capita household income, which includes all income sources and accounts for both heterogeneous income situations and the number of household members when comparing different households. We did not use a continuous variable but rather clustered income into ranges.

Another important variable is "experience with long-term care", as experienced interviewees have an informational advantage, and we base one of our hypotheses on this fact. This variable is a dummy variable and equal to one if, in the household of individual $i$, a need for long-term care exists. Two additional factors that yield an informational advantage that we included are "political interest" and "general level of

\footnotetext{
${ }^{20}$ Weinstein (1980, pp. 813, 818-819), Weinstein (1989, p. 1232).

${ }^{21}$ McCall et al. (1998, p. 194).
} 
education" (low, middle or high). "Political interest" is coded as an ordinal variable from one (none) to four (very strong).

We also include a set of conventional control variables in the regression, which may be correlated with the dependent variable.

\section{Results}

We begin this section by evaluating the descriptive statistics of the data prior to going deeper into detail and using more sophisticated analytics. Generally, we will focus on and highlight the effects of the introduction of compulsory long-term care insurance by looking at changes in the different clusters between 1992 and 2002. As we mentioned in the third section, we will also refer to separate regressions if they provide additional insights. We will try to verify or reject our hypotheses based on the results presented in this section.

A first examination of the data is displayed in Figure 3, showing the relative frequency of the different perception clusters in 1992, 1997 and 2002. The mass of the distribution shifts from the lower values to higher values over time. This is an expected result as long-term care insurance unburdens a large segment of the population. Only the "very good" cluster exhibits decreasing numbers, but due to its small size, it does not significantly influence the positive shift. To examine this apparent shift and the influence of several other variables in more detail, we will focus on the regression analysis presented in the section 'Data, methodology and hypothesis' after the initial descriptive evaluation. To ensure that this positive shift is not the result of a general

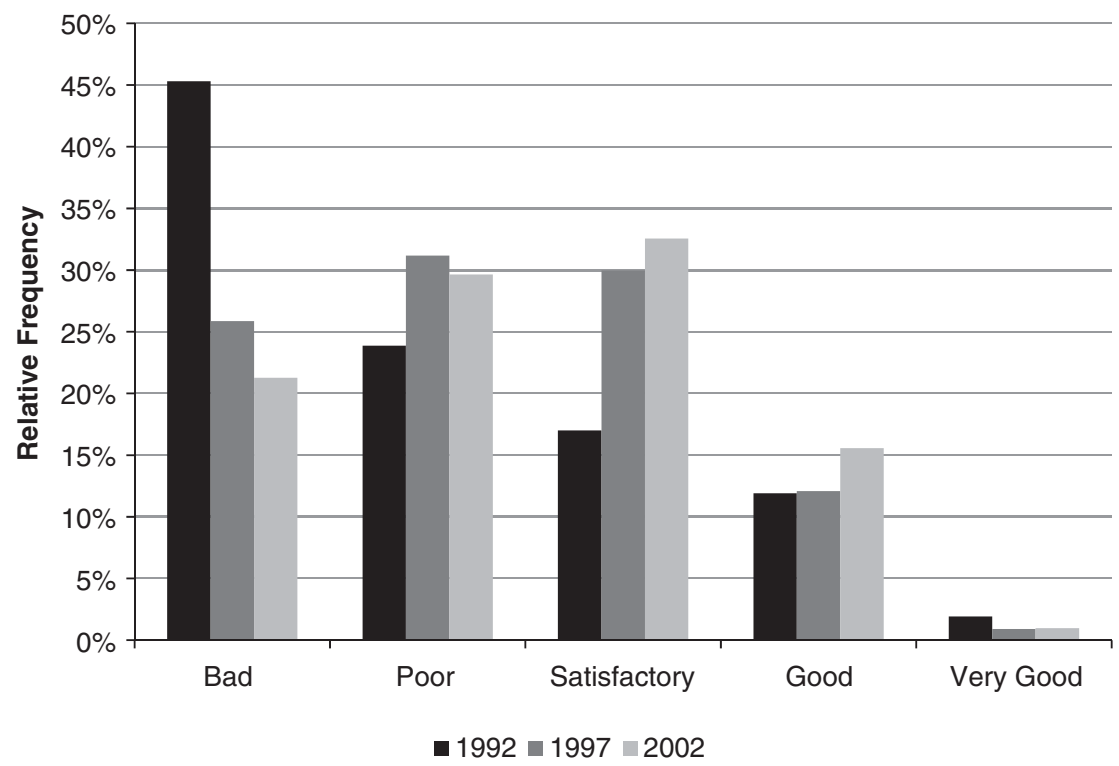

Figure 3. Perception of financial security concerning long-term care (relative frequencies). 
Financial Security in Case of

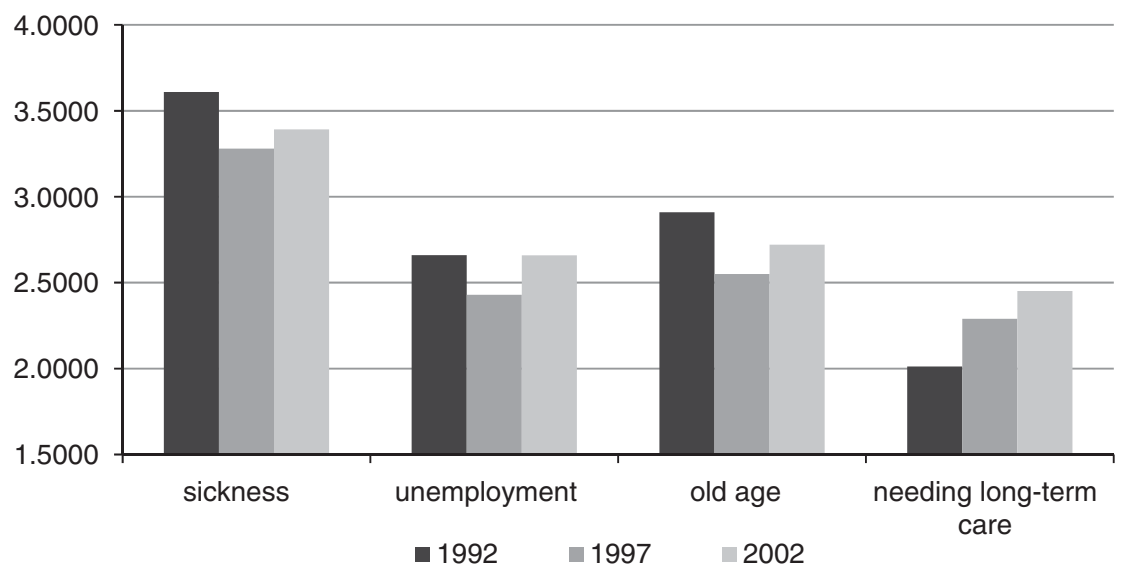

Figure 4. Mean value of perception of financial security.

positive trend in the perception of financial security, we compare the perception of financial security in the case of long-term care needs with the perception of financial security in the case of old age, sickness and unemployment, which are also covered by the SOEP. Figure 4 displays the mean values of the perception of financial security in 1992, 1997 and 2002 for all four cases. ${ }^{22}$ The mean value in the case of long-term care needs increases from 1992 to 1997, and the mean value decreases for all other cases. Therefore, there appears to be a general negative shift in the assessment of financial security; however, our results verify a positive impact on financial security in the case of long-term care needs due to the introduction of compulsory long-term care insurance. Comparing 1997 and 2002, the mean values represent a positive shift in the assessment of financial security for all cases, which therefore support a general positive trend from 1997 to 2002 . Because the trend is positive for all cases, the positive shift in the case of long-term care needs from 1992 to 1997 appears to be stable, at least in the observed sample.

As noted in the section 'Overview of German social long-term care insurance', compulsory long-term care insurance had a particularly positive effect on the midincome subgroup, which had to bear all the costs of long-term care prior to the introduction of social long-term care insurance. Prior to 1995, financial support of long-term care needs was only supplied by voluntary private insurance. Therefore, we expect these clusters to have an increased level of perception relative to the average. This expected effect must be further examined, so we split the population into household-income per capita clusters and observed how their perception of financial security changed over time for specific subgroups in the regression analysis. The clustering split the sample into five groups: $[0,500),[500,1,000),[1,000,2,000)$, $[2,000,3,000)$ and $[3,000, \infty)$.

${ }^{22}$ Although the mean value is not a probable measure for ordinal data, it is sufficient to identify a trend. 
Table 1 Relative frequency of perception for the $(0, € 500)$ cluster of household income per capita

\begin{tabular}{lccc}
\hline Perception & $1992($ in $\%)$ & 1997 (in \%) & 2002 (in \%) \\
\hline Bad & 51.89 & 30.19 & 26.60 \\
Poor & 25.00 & 35.85 & 31.58 \\
Satisfactory & 10.38 & 20.13 & 29.66 \\
Good & 11.32 & 13.21 & 11.68 \\
Very good & 1.42 & 0.63 & 0.48 \\
\hline
\end{tabular}

Table 1 displays the perception change from 1992 to 2002 for the cluster that has less than $€ 500$ of household income per capita. This is a special group with regard to the changes that took place in 1995. As described in the section 'Overview of German social long-term care insurance', it is more likely for this group to receive social security benefits in the case of long-term care needs, relying on the aforementioned "Hilfe zur Pflege". This subgroup did not experience any major changes in coverage with the introduction of the new insurance. Comparing the change in perception for this subgroup with the change in perception for the overall sample, a similar trend can be observed in the data, which leads to the assumption that the perception of financial security is also positively affected by the introduction of social long-term care insurance for this special subgroup.

Table 2 presents the regression results of the pooled ordered probit regression.

\section{Introduction of compulsory long-term care insurance}

The first result to note is that the coefficients for the year dummy variables for 1997 and 2002 are significant on the 1 per cent level and positive, suggesting that the general view of financial risk associated with long-term care needs improved after the introduction of compulsory long-term care insurance. This is also indicated in Figures 3 and 4 where the shift of the distribution to a higher mean suggests the same conclusion. As mentioned before, due to the general negative trend between 1992 and 1997 in the perception of financial security, the coefficients of the year dummy variables are likely underestimated. These results verify our hypothesis that due to individual risk aversion, long-term care insurance improves financial security.

\section{Income}

Now we explore the regression results with regards to our second hypothesis of income positively influencing an individual's assessment of financial security.

Note that the absolute values of the coefficient monotonously increase with the level of household income per capita in 1992. The coefficient for the [500,1,000) cluster is insignificant, implying that it yields the same effect if household income per capita is drawn from $[0,500)$ in 1992. The assessment of financial security increasing with income is also observed in 2002. The interaction dummy variables for 1997 are all insignificant, verifying the conjecture that income is now regarded as minor factor when assessing financial security. Looking at the interaction dummy variables for 2002 
Table 2 Regression results, confidence levels denoted by *: 10\%, **: 5\%, ***: 1\% level

\begin{tabular}{|c|c|c|}
\hline \multirow[t]{2}{*}{ Variable } & \multicolumn{2}{|c|}{ Ordered probit } \\
\hline & Coefficient & Standard error \\
\hline Year 1997 & $0.402^{* * *}$ & 0.152 \\
\hline Year 2002 & $0.595 * * *$ & 0.118 \\
\hline Experience with long-term care & -0.049 & 0.087 \\
\hline Experience with long-term care* (Year1997) & -0.048 & 0.113 \\
\hline Experience with long-term care* (Year2002) & $0.207 * *$ & 0.106 \\
\hline Having children under 16 & $0.254 * * *$ & 0.039 \\
\hline Having children under $16^{*}$ (Year1997) & $-0.209 * * *$ & 0.050 \\
\hline Having children under $16^{*}$ (Year2002) & $-0.224 * * *$ & 0.048 \\
\hline Widowed (Reference category: married) & -0.127 & 0.091 \\
\hline Widowed* (Year1997) & $0.334 * * *$ & 0.111 \\
\hline Widowed* (Year2002) & $0.238 * *$ & 0.105 \\
\hline Political interest & $-0.062 * * *$ & 0.021 \\
\hline Political interest* (Year1997) & 0.041 & 0.028 \\
\hline Political interest* (Year2002) & 0.029 & 0.027 \\
\hline \multicolumn{3}{|c|}{ Household income per capita (Reference category: Income <500) } \\
\hline$[500,1,000)$ & 0.079 & 0.092 \\
\hline$[500,1,000)^{*}($ Year 1997$)$ & -0.043 & 0.136 \\
\hline$[500,1,000)^{*}($ Year2002) & 0.021 & 0.098 \\
\hline$[1,000,2,000)$ & $0.203 * *$ & 0.092 \\
\hline$[1,000,2,000)^{*}($ Year 1997) & -0.044 & 0.136 \\
\hline$[1,000,2,000)^{*}($ Year2002) & 0.049 & 0.101 \\
\hline$[2,000,3,000)$ & $0.264 * * *$ & 0.102 \\
\hline$[2,000,3,000)^{*}($ Year 1997) & -0.099 & 0.148 \\
\hline$[2,000,3,000)^{*}($ Year2002) & $0.355^{* *}$ & 0.145 \\
\hline$\geqslant 3,000$ & $0.643 * * *$ & 0.127 \\
\hline$\geqslant 3,000 *($ Year 1997) & -0.001 & 0.180 \\
\hline$\geqslant 3,000 *($ Year2002) & -0.088 & 0.241 \\
\hline \multicolumn{3}{|c|}{ Education (Reference group: average education level) } \\
\hline Low education level & $0.110 * * *$ & 0.034 \\
\hline Low education level* (Year1997) & 0.055 & 0.046 \\
\hline Low education level* (Year2002) & -0.015 & 0.044 \\
\hline High education level & -0.064 & 0.071 \\
\hline High education level* (Year1997) & -0.070 & 0.092 \\
\hline High education level* (Year2002) & 0.044 & 0.085 \\
\hline
\end{tabular}

Log-Likelihood: $-24,019.717$

Pseudo- $R^{2}: 0.0368$

Number of obs: 17,963

Additional control variables: age, sex, marital status, employment status, kind of health insurance, perception of health status, financial assets, house owner.

yields an interesting result. The coefficients rise to levels similar to before the introduction of social long-term care insurance and are significant. The rationale for this may be similar to the argument regarding the variable experience with long-term care. While that group had an informational advantage by directly observing the situation immediately after the introduction, inexperienced individuals appear to trust the newly implemented governmental intervention and, as a result, rely less on their 
respective income, as we expected. In the following years, mass media headlines suggested that insurance was experiencing financial difficulties, stoking fears of insufficient funds and a return to the need for individual safety nets.

As the income cluster of $[0,500)$ cannot be directly observed because it is the reference group for the regression, the regression is inconclusive when interpreting the introduction effect for this income group. Therefore, only the descriptive analysis in Table 1 may be used to derive any conclusion. As mentioned above, due to the general trend, which is also present for the $<€ 500$ per capita income cluster, we may deduce that even the lower income group assesses its financial security in the case of long-term care needs significantly better than before the introduction and similar to all other income groups. This is not intuitive as the coverage, or security, for a large part of this group is not actually improving.

\section{Experience with long-term care}

According to our third hypothesis, our assumption can be upheld relatively but not absolutely. Experience with long-term care was not a significant factor prior to the introduction of social insurance. This implies that, contrarily to our first hypothesis, experience had no negative impact on the assessment of financial security for the aggrieved party.

Looking at the sign and coefficient of the change in influence of the experience with long-term care variable, the influence did not change in 1997 but increased significantly in 2002. These effects yield the result stated earlier and in our hypothesis in relative form. This fact may be interpreted as a hint towards the effectiveness of the introduction of social long-term insurance. However, regarding the value and significance level of the variable in 1997, one might suspect that the group of individuals experienced with longterm care are affected by a slow and problematic start. ${ }^{23}$ In addition, they could directly observe the effect of the introduction and therefore assess their own situation during the implementation. The fact that the introduction was perceived positively over the longterm is a result that was expected and confirmed by the data. The significant difference does not directly imply that experience was a significant influence for long-term care in 2002 .

We also look at the experience coefficient in the separated 1997 and 2002 regression, the results of which are presented in Table 3. The influence is negative and significant at the 10 per cent level in 1997 as well as significant and positive on the 1 per cent level in 2002. This confirms the results of the pooled regression. We also expect the assessment of financial risk prior to the introduction to be distorted in this subgroup as the individual burden was expected to impair the perception of financial risk. This is clearly not the case as the respective coefficient is insignificant. Thus, the experience with long-term care in individual households did not have any influence in 1992.

\footnotetext{
${ }^{23} \operatorname{Dietz}(1992$, p. 13).
} 
Table 3 Regression results, confidence levels denoted by *: 10\%, **: 5\%, ***: 1\% level

\begin{tabular}{|c|c|c|c|}
\hline \multirow[t]{2}{*}{ Variable } & Ordered probit 1992 & Ordered probit 1997 & Ordered probit 2002 \\
\hline & \multicolumn{3}{|c|}{ Coefficient (standard error) } \\
\hline Experience with long-term care & $\begin{array}{r}-0.040 \\
(0.087)\end{array}$ & $\begin{array}{r}-0.122 * \\
(0.073)\end{array}$ & $\begin{array}{l}0.185 * * * \\
(0.063)\end{array}$ \\
\hline Having children under 16 & $\begin{array}{l}0.210^{* * *} \\
(0.046)\end{array}$ & $\begin{array}{l}0.071^{*} \\
(0.040)\end{array}$ & $\begin{array}{l}0.015 \\
0.038\end{array}$ \\
\hline Widowed (Reference category: married) & $\begin{array}{c}-0.115 \\
(0.098)\end{array}$ & $\begin{array}{l}0.210^{* * * *} \\
(0.073)\end{array}$ & $\begin{array}{l}0.137 * * \\
(0.062)\end{array}$ \\
\hline Political interest & $\begin{array}{r}-0.043^{* *} \\
(0.0215)\end{array}$ & $\begin{array}{c}-0.031 \\
(0.019)\end{array}$ & $\begin{array}{c}-0.036^{* *} \\
(0.017)\end{array}$ \\
\hline \multicolumn{4}{|c|}{ Household income per capita (Reference category: Income $<500)$} \\
\hline$[500,1,000)$ & $\begin{array}{c}0.081 \\
(0.093)\end{array}$ & $\begin{array}{c}0.013 \\
(0.101)\end{array}$ & $\begin{array}{l}0.110 * * * \\
(0.035)\end{array}$ \\
\hline$[1,000,2,000)$ & $\begin{array}{l}0.196^{* *} \\
(0.094)\end{array}$ & $\begin{array}{c}0.138 \\
(0.102)\end{array}$ & $\begin{array}{l}0.269^{* * *} \\
(0.045)\end{array}$ \\
\hline$[2,000,3,000)$ & $\begin{array}{l}0.241^{* *} \\
(0.104)\end{array}$ & $\begin{array}{c}0.147 \\
(0.109)\end{array}$ & $\begin{array}{l}0.660 * * * \\
(0.107)\end{array}$ \\
\hline$\geqslant 3,000$ & $\begin{array}{l}0.555^{* * * *} \\
(0.131)\end{array}$ & $\begin{array}{l}0.664^{* * * *} \\
(0.132)\end{array}$ & $\begin{array}{l}0.594^{* * * *} \\
(0.209)\end{array}$ \\
\hline \multicolumn{4}{|c|}{ Education (Reference group: average education level) } \\
\hline Low education level & $\begin{array}{l}0.110^{* * *} \\
(0.036)\end{array}$ & $\begin{array}{l}0.154 * * * \\
(0.031)\end{array}$ & $\begin{array}{l}0.010^{* * *} \\
(0.030)\end{array}$ \\
\hline High education level & $\begin{array}{c}-0.101 \\
(0.073)\end{array}$ & $\begin{array}{c}-0.110^{*} \\
(0.060)\end{array}$ & $\begin{array}{c}-0.021 \\
(0.049)\end{array}$ \\
\hline Log-Likelihood & -6405.9055 & -7976.8957 & -9371.3532 \\
\hline Pseudo- $R^{2}$ & 0.0177 & 0.0276 & 0.0314 \\
\hline Number of observations & 4,971 & 6,017 & 6,975 \\
\hline
\end{tabular}

Additional control variables: age, sex, marital status, employment status, kind of health insurance, perception of health status, financial assets, house owner.

\section{Children and widows}

Although the following variables are not covered by the initially proposed hypotheses, we want to highlight a set of control variables that yield interesting results. The first of which is the influence of children. As mentioned in the introduction, families with children should be less concerned about old age and nursing needs, as families were traditionally responsible for this burden and generally bore the financial risk as payback for the transfers they received while growing up. In 1992, the coefficient was significant and positive, which is probably explained by the traditionalist view discussed above. The assessment of their financial risk depended largely on whether children existed in the respective household. This picture changes after the introduction of social long-term care insurance. Both change coefficients are significant and negative. Therefore, it appears that children did not matter in the assessment of financial risk in the case of long-term care needs. The rationale for this finding is not obvious. First, the introduction of long-term care insurance may be a major factor in 
640

this development. In fact, a large fraction of the financial obligations for long-term care is borne by compulsory insurance after 1995. As a result, the need for financial support from one's children is of decreasing importance. There are other trends that may be partially responsible for these observations. For example, the number of children has significantly decreased, nullifying the effect of "several shoulders" bearing the costs of long-term care. Keep in mind that our question only covers the financial aspects of long-term care, not the fact that children provide important mental support when individuals are in need. Therefore, this effect is not reflected in our results.

The next variable of interest is also not covered by our hypotheses, but we wanted to present the results in this context. Being a widow significantly influences the individual assessment of financial risk after the introduction of social long-term care insurance. Compared to married individuals, the coefficient is insignificant in 1992; however, the change in assessment for 1997 and 2002 is positive and highly significant. The results suggest that before the introduction of long-term care insurance, there was no significant difference in the assessment of financial risk between married or widowed individuals. However, a widowed individual has a more optimistic view of their financial security in the case of long-term care needs compared to a married individual. This is an unexpected result in absolute terms. One explanation for this positive change in the assessment of financial security may be a result of experience with public benefits, such as widow pensions. This positive experience could have generally strengthened the confidence in federal benefits, leading to an improving assessment of financial security.

\section{Education and political interest}

Two other variables also produced interesting results: level of education and level of political interest. It is interesting to note that with a higher level of education and political interest, the assessment of financial security declines. This is most likely because individuals with more education demand more information. Although this is not surprising, the opposite argument could have also been made. As information sources are limited in the lower educated social stratum, one could expect those individuals to be more susceptible to manipulation by the media. However, this is not verified in our data set. Similar to the case of widowed individuals, this result may be due to greater exposure to social benefits and the positive assessment of those benefits. Additional research in this direction could be enlightening.

\section{Robustness of the results}

To check our results for robustness, we performed the same regressions on subsamples of the original sample. Thirty per cent of the observations were randomly dropped, and the analysis was conducted several times. After 20 repetitions, the results were compared. We could not identify any significantly different outcomes in any test regressions. Only in the case where too many people of the small group of experienced participants were dropped by the algorithm, the corresponding variable became insignificant, but more importantly never changed signs. Furthermore, the separate regressions reproduced the results of the pooled regression, where comparable. 


\section{Conclusion}

We gained meaningful insight into the validity of a large proportion of our hypotheses. As expected, the feeling of financial security is an increasing function in income. In addition, this effect was diminished with the introduction of longterm care insurance in the short term, while returning to formerly high levels in the long run. Experience with long-term care and an informational edge have a positive influence on the perception of financial security with the introduction of compulsory insurance; however, this occurs on a higher level in the long run than we originally conjectured.

The results of our regression analysis illustrate that the perception of financial security in the case of long-term care needs increased in all segments of the population after introducing compulsory long-term care insurance. This is currently not reflected in public discussions because it focuses on the shortcomings of the current benefit schedule of this social insurance. As previously mentioned, the discussion primarily focuses on directly measurable dimensions, narrowing the argument to the state of insurance itself. Future reform should therefore be accompanied by a more robust information policy. A specific subgroup in our sample highlights the benefits of a better information policy. By directly observing federal support and other benefits, they gain access to more information. As a result, individuals who have experienced long-term care at home assess the situation better. This information deficit can be closed by providing more transparency and involving the insured, which will likely lead to no necessity of compulsory private endorsements.

It is clear that the introduction of a new public benefit system appears to improve an individual's assessment of his or her financial security. This should be kept in mind when thinking about merging health insurance and long-term care insurance, as it has been recently proposed by several parties. Knowledge of the existence of a support system appears to play a significant role in assessment, which can be seen in the low-income cluster of our analysis. The primary change for a large segment of the population is just a name change. This subjective reasoning may also be used in another way: by building a joint institution, the demand for additional private insurance could be artificially increased. Supplementing the current system with private insurance contracts has often been publically discussed (e.g., in the Ruerup commission).

Further research could perform a detailed analysis of how different factors influence individual assessments of financial security. Especially regarding our result of improving perception within the low-income group, further closer analysis is capable of producing additional insights. Another study could analyse the influence of wealth by using clusters of monetary commitments in different asset classes.

Lastly, we want to point out some limitations to our study. As it was not possible to observe if individuals had private long-term care insurance prior to the introduction of social long-term care insurance, we encountered an identification problem. This could limit the validity of our results. However, as mentioned in the section 'Overview of German social long-term care insurance', prior to the introduction, approximately 250,000 private contracts existed, making the effect negligible. 


\section{References}

BMG Bundesministerium fuer Gesundheit (Ministry of Health) (2008a) 'Berichte zur Entwicklung der Plfegeversicherung, 4. Bericht (Report on the Development of the Social Long-Term Care Insurance, 4. Edition)', from http://www.bmg.bund.de, accessed 28 January 2010.

BMG Bundesministerium fuer Gesundheit (Ministry of Health) (2008b) 'Leistungsempfaenger der sozialen Pflegeversicherung am Jahresende nach Pflegestufen 1995-2008 (Recipients of Benefits of the Social Long-Term Care Insurance by End of the Year and Levels of Care 1995-2008)', from http://www .bmg.bund.de, accessed 28 January 2010.

BMG Bundesministerium fuer Gesundheit (Ministry of Health) (2009a) 'Finanzentwicklung in der sozialen Pflegeversicherung. Ist-Ergebnisse ohne Rechnungsabgrenzung (Financial Development of the Social Long-Term Care Insurance)', from http://www.bmg.bund.de, accessed 28 January 2010.

BMG Bundesministerium fuer Gesundheit (Ministry of Health) (2009b) 'Zahlen und Fakten zur Pflegeversicherung (07/09) (Numbers and Facts on the Long-Term Care Insurance)', from http://www .bmg.bund.de, accessed 28 January 2010.

BMGS Bundesministerium fuer Gesundheit und Soziales (Ministry of Health and Social Affairs) (2003) 'Nachhaltigkeit in der Finanzierung der Sozialen Sicherungssysteme, Bericht der Kommission (Sustainability in Financing of Social Security, Report of the Commission)', from http://www.bmas .de/portal $/ 538 /$ property $=p d f /$ nachhaltigkeit_in_der_finanzierung_der_sozialen_sicherungssysteme.pdf, accessed 28 January 2010.

Breyer, F. (1991/1992) 'Verteilungswirkungen unterschiedlicher Formen der Pflegevorsorge (Distributional impacts of alternative forms of provision long-term care)', Finanzarchiv 49: 84-103.

Brown, J.R. and Finkelstein, A. (2007) 'Why is the market for long-term care insurance so small?' Journal of Public Economics 91(10): 1967-1991.

Buchholz, W. and Wiegard, W. (1992) 'Allokative Ueberlegungen zur Reform der Pflegevorsorge (Allocative considerations concerning the reform of provision for long-term care)', Jahrbuecher fur Nationaloekonomie und Statistik 209: 441-457.

Costa-Font, J., Garcia-Gonzalez, A. and Font-Vilalta, M. (2008) 'Relative income and attitudes towards long-term care financing', The Geneva Papers on Risk and Insurance-Issues and Practice 33(4): 673-693.

Courbage, C. and Roudaut, N. (2008) 'Empirical evidence on long-term care insurance purchase in France', The Geneva Papers on Risk and Insurance - Issues and Practice 33(4): 645-658.

Dietz, B. (1992) Die Pflegeversicherungen-Ansprüche, Wirklichkeiten und Zukunft einer Sozialreform, Wiesbaden: VS Verlag für Sozialwissenschaften.

Doerpinghaus, H.I. and Gustavson, S.G. (2002) 'Long-term care insurance purchase patterns', Risk Management and Insurance Review 5(1): 31-43.

Eisen, R. (1992) 'Alternative Sicherungsmőglichkeiten bei Pflegebeduerftigkeit (Alternative possibilities for ensuring the risk of long-term care)', Sozialer Fortschritt 41: 236-241.

Geraedts, M., Heller, G.V. and Harrington, C.A. (2000) 'Germany's long-term-care insurance: Putting a social insurance model into practice', The Milbank Quarterly 78(3): 375-401.

Goetting, U., Haug, K. and Hinrichs, K. (1994) 'The long road to long-term care insurance in Germany', Journal of Public Policy 14(3): 285-309.

Guillén, M. and Pinquet, J. (2008) 'Long-term care: Risk description of a Spanish portfolio and economic analysis of the timing of insurance purchase', The Geneva Papers on Risk and Insurance-Issues and Practice 33(4): 659-672.

Hershey, J., Kunreuther, H., Schwartz, J.S. and Williams, S.V. (1984) 'Health insurance under competition: Would people choose what is expected?' Inquiry 21(4): 349-360.

Holtgrave, D.R. and Weber, E.U. (1993) 'Dimensions of risk perception for financial and health risks', Risk Analysis 13(5): 553-558.

Kunreuther, H. (1978) Disaster Insurance Protection: Public Policy Lessons, New York: John Wiley \& Sons, Inc.

McCall, N., Mangle, S., Bauer, E. and Knickman, J. (1998) 'Factors important in the purchase of partnership long-term care insurance', Health Service Research 33(2): 187-203.

OECD (2008) 'Conceptual framework and definition of long-term care expenditure', from http:// www.oecd.org/dataoecd/24/58/40760216.pdf, accessed 27 March 2003. 
Parker, G. and Clarke, H. (1997) 'Will you still need me, will you still feed me? Paying for care in old age', Social Policy \& Administration 31(2): 119-135.

Pauly, M.V. (1990) 'The rational nonpurchase of long-term-care insurance', Journal of Political Economy 98(1): 153-168.

Statistisches Bundesamt (2009) Statistik der Sozialhilfe-Hilfe zur Pflege 2007 (Statistics of Social Assistance-Help for Care 2007, in German), Wiesbaden: Statistisches Bundesamt.

Wagner, G.G., Frick, J.R. and Schupp, J. (2007) 'The German socio-economic panel study (SOEP)—Scope, evolution and enhancements', Schmollers Jahrbuch 127(1): 139-170.

Weinstein, N.D. (1980) 'Unrealistic optimism about future life events', Journal of Personality and Social Psychology 39(5): 806-820.

Weinstein, N.D. (1989) 'Optimistic biases about personal risk', Science 246(4935): 1232-1233.

Winkelmann, R. and Boes, S. (2006) Analysis of Microdata, Berlin: Springer.

Zweifel, P. and Strüwe, W. (1998) 'Long-term care insurance in a two-generation model', The Journal of Risk and Insurance 65(1): 13-32.

\section{About the Authors}

Andy Zuchandke studied economics at Otto-von-Guericke Universität Magdeburg. $\mathrm{He}$ is now working at the Institute for Insurance of the Leibniz Universität, Hannover. Before entering the Institute he worked for four years in the bank industry. His research interests are applied econometrics, risk management and insurance economics.

Sebastian Reddemann studied mathematics at Leibniz Universität, Hannover. After completing the Math Part III course in Cambridge, U.K., he is now working at the Center for Risk and Insurance of the Leibniz Universität, Hannover. He has published in refereed journals. His research interests are financial econometrics, financial math and risk management.

Simone Krummaker is lecturer and research associate at the Center for Risk and Insurance, Leibniz University of Hannover. She studied Economics and Management at the University of Hannover. Before entering the Center she worked for ten years in the insurance industry. Her research interests focus mainly on individual and corporate insurance demand and risk management.

J.-Matthias Graf von der Schulenburg studied economics and law in Göttingen. He received his $\mathrm{PhD}$ from the Institute for International Economic Relations at the LMU in Munich. Following one year as Assistant Professor at Princeton University, he directed the International Institute for Management in Berlin and now leads the Institute for Risk and Insurance at the Leibniz Universität, Hannover. He has received numerous awards and has published in major economic and management journals. 